\title{
Как может рассуждать компьютер в духе булевой многозначности
}

\author{
К. И. БАХТИЯРОВ
}

Памяти дочери посвящается

\begin{abstract}
How a computer may think? The non-classical manyvaluedness can be presented by means of classical logic. We use $F=$ -1 as a negative number for false, and the logical zero is released for uncertainty $N=0$ which is better to be accepted by $\boldsymbol{a}$ computer $\boldsymbol{b} y$ default than a presumption of lie. Uncertainty $N=0=\frac{0}{1}$ forms the triad $\nabla_{\mathbf{N}}:-1, \frac{0}{1}, 1$ where false $\mathbf{F}$ gives $\frac{-1}{1} \vee \frac{0}{1}=\frac{0}{1}$. Nonsense $B=0^{\prime}=$ $\frac{1}{0}$ forms the inverse triad $\triangle_{\mathbf{B}}: 1,0^{\prime},-1^{\prime}$ where $\mathbf{F}^{\prime}$ gives $\frac{1}{-1} \vee \frac{1}{0}=\frac{1}{0}$. Two triads generate FIVE system, where $N \vee B=0 \vee 0^{\prime}=\frac{0}{1} \vee \frac{1}{0}=\frac{1}{1}$. Operations are done componentwise. The letters of a genetic code are taken for a sample: $A$ (adenine) as a maximum, $u$ (uracil) as a weak minimum, and also the inverted letters: $V$ as a minimum, $n$ as a weak maximum. The Matrix of Complementarity, columns of which represent complementary pairs, has been constructed under laws of creation of a living organism. The complete block $\Psi$ characterizes dependence on Last Name-dominants $A$ and $V$ Isomorphism of matrices of a genetic code and mental types shows predisposition of characters, in many respects determined by their genetic code. It is offered the arithmetizaton of modal logic on the basis of the Matrix of Complementarity.
\end{abstract}

Ключевые слова: пятизначная бирешетка, ложь-нонсенс, самодуальность инверсии, комплементарность, генкод, доминанты, психогенетика

\section{1 Арифметизация практической логики Белнапа}

Математика (в отличие от грамматики) не любит исключений. П.С. Александров. Лекции по аналитической геометрии

Для реализации идеи булевой многозначности будем отталкиваться (сначала опираться, а потом делать качественный скачок) от четырех значений, которые использовались Булем в логике. На столетии его «Законов мысли» идея булевой многозначности подчеркивалась Р. Фейсом и согласно его интер- 
претации (в полном соответствии с правилами математики) следовало считать $\frac{1}{1}=1$ истинным, $\frac{0}{1}=0$ ложным, $\frac{0}{0}$ неопределенным, $\frac{1}{0}$ бесконечным значением [21]. Рассмотрим первые три значения. Если использовать идею Я. Лукасевича о покомпонентном выполнении операций в четырехзначной логике, то для этих четырех значений имеем $\frac{0}{1} \vee \frac{1}{1}=\frac{1}{1}$ и $\frac{0}{0} \vee \frac{1}{1}=\frac{1}{1}$, но $\frac{0}{0} \vee \frac{0}{1}=\frac{0}{1}(*) ? !$ Действуя формально, в последнем случае получаем ложное значение $F$ вместо неопределенности. Ведь должно быть $N \vee F=N(* *)$. Тогда Лукасевич в трехзачной логике записывает $\frac{1}{2} \vee 0=\frac{1}{2}$. Обстоятельный обзор дан в монографии А.С. Карпенко «Развитие многозначной логики» [11]. Однако введение дробного значения $\frac{1}{2}$ означает полный отказ от концепции булевой многозначности, исповедующей принцип цифровой бинарности (только цифры 0 и 1). Ее не следует путать с числовой бинарностью и было бы правильнее называть логической многомерностью. Можно заметить родство этой логики с конечными геометриями.

Исторический опыт показывает, что обогащение математического аппарата всегда проводилось путем обобщения обратных арифметических операций на случаи, когда они невозможны. Лазарь Карно говорил: «Попробуйте взять 5 яблок со стола, где лежат 3 яблока». Автор полагает, что для обозначения лжи как отрицания истины более естественно использовать отрицательное число -1 . Тогда вместо формулы $(* *)$ будем просто иметь $0 \vee-1=0$, формулу $(* * *)$. Логический нуль освобождается для неопределенности (принятие которой компъютером по умолчанию лучше презумпции лжи) [3]. Неопределенности Белнапа $N=$ None (ни истинно, ни ложно) [3] будет соответствовать значение $0=\frac{0}{1}$. Неопределенность $\mathbf{N}$ задает тройку значений: $0,1,-1$ (Лукасевич Ł3) с ложью-ошибкой $F=-1=\frac{-1}{1}$. Нонсенсу Белнапа $B=B o t h$ (и истинно, и ложно) [3] будет соответствовать значение $0^{\prime}=\frac{1}{0}$. Нонсенс В задает обратную тройку значений: $0^{\prime}, 1,-1^{\prime}$ (анти-Лукасевич $\ell^{\prime} 3$ ) с ложью-нонсенсом (граничащей с абсурдом) $F^{\mathbf{B}}=F^{\prime}=-1^{\prime}=\frac{1}{-1}$. Для обозначения обратных величин вводится апостроф: $x^{\prime}=x^{1}=\frac{1}{x}$. Для обратных величин получаем $0^{\prime} \vee-1^{\prime}=0^{\prime}$, так как $\frac{1}{0} \vee \frac{1}{-1}=\frac{1}{0}$. Этот результат $0^{\prime}=0^{-1}=\frac{1}{0}$ является следствием покомпонентного выполнения операций. 
Унарные связки для логической инверсии «'» и отрицания «-» определяются нами следующей таблицей:

\begin{tabular}{|r|r|r|}
\multicolumn{1}{c}{$A$} & \multicolumn{1}{c}{$A^{\prime}$} & \multicolumn{1}{c}{$-A$} \\
\hline$-1=\frac{-1}{1}$ & $-1^{\prime}=\frac{1}{-1}$ & $1=\frac{1}{1}$ \\
\hline $0=\frac{0}{1}$ & $0^{\prime}=\frac{1}{0}$ & $0=\frac{0}{1}$ \\
\hline $1=\frac{1}{1}$ & $1=\frac{1}{1}$ & $-1=\frac{-1}{1}$ \\
\hline $0^{\prime}=\frac{1}{0}$ & $0=\frac{0}{1}$ & $0^{\prime}=\frac{1}{0}$ \\
\hline$-1^{\prime}=\frac{1}{-1}$ & $-1=\frac{-1}{1}$ & $1=\frac{1}{1}$ \\
\hline
\end{tabular}

В итоговой таблице дизъюнкции выделены триада $\nabla_{\mathbf{N}}$ и обратная триада' $\triangle^{\mathbf{B}}$ для $\mathrm{Ł} 3$ и $£^{\prime} 3$, которые совместно порождают пятизначную бирешетку $F I V E$. Образно говоря, склеивание по единственной истине $(T)$ знака римской пятерки $V$ и ее перевернутого знака порождает римскую десятку $X$. Так удается избежать парадокса гексаграммы, называемой звездой Давида.

\begin{tabular}{|c|c|c|c|c|c|}
\hline V & -1 & 0 & 1 & $0^{\prime}$ & $-1^{\prime}$ \\
\hline-1 & -1 & 0 & 1 & 1 & 1 \\
\hline 0 & 0 & 0 & 1 & 1 & 1 \\
\hline 1 & 1 & 1 & 1 & 1 & 1 \\
\hline $0^{\prime}$ & 1 & 1 & 1 & $0^{\prime}$ & $0^{\prime}$ \\
\hline$-1^{\prime}$ & 1 & 1 & 1 & $0^{\prime}$ & $-1^{\prime}$ \\
\hline
\end{tabular}

\begin{tabular}{l|lllll}
$\vee$ & \multicolumn{1}{l}{$F$} & $N$ & $T$ & $B$ & $F^{\prime}$ \\
\cline { 2 - 5 }$F$ & $F$ & $N$ & $T$ & $T$ & $T$ \\
$N$ & $N$ & $N$ & $T$ & $T$ & $T$ \\
\cline { 3 - 5 }$T$ & $T$ & $T$ & $T$ & $T$ & $T$ \\
$B$ & $T$ & $T$ & $T$ & $B$ & $B$ \\
$F^{\prime}$ & $T$ & $T$ & $T$ & $B$ & $F^{\prime}$ \\
\cline { 2 - 5 } & & & &
\end{tabular}

В общей логической алгебре следует отличать ложь-нонсенс $\mathbf{F}^{\prime}=-1^{\prime}=\frac{1}{-1}$ и ложь-ошибку $F=-1=\frac{-1}{1}$, потому что это разные упорядоченные пары. Дизъюнкция с нонсенсом В для лжи-нонсенса $\mathbf{F}^{\prime}$ дает нонсенс $\mathbf{B}$, а когда имеем ложьошибку F, то истину T. Образно говоря, они находятся в разных окрестностях, являются аналогами бесконечно-больших и бесконечно-малых. Это важно, поскольку в отношениях вида $\frac{x}{y}$ (которые в логике являются проективными координатами) операции производятся покомпонентно. Две триады имеют общее значение истины, поскольку $\mathbf{T}=\mathbf{T}^{\prime}=\frac{1}{1}$. Они отличаются парами неопределенностей $N=0=\frac{0}{1}, F=-1=\frac{-1}{1}$ и абсурдностей 
$B=0^{\prime}=\frac{1}{0}, F^{\prime}=-1^{\prime}=\frac{1}{-1}$. Покажем, что для алгебры логики, в которой операции выполняются покомпонентно, недостаточно системы FOUR четырехзначной логики. Действительно, $-1^{\prime} \vee 0^{\prime}=0^{\prime}$, но $-1 \vee 0^{\prime}=1$, так как $\frac{-1}{1} \vee \frac{1}{0}=\frac{1}{1}$. Вообще, $a \vee b^{\prime}=1$, ибо $\frac{a}{1} \vee \frac{1}{b}=\frac{1}{1}$. В частности, $0 \vee 0^{\prime}=1$, т.е. $N \vee B=T$, так как $\frac{0}{1} \vee \frac{1}{0}=\frac{1}{1}$.

Итак, для выполнения покомпонентных операций алгебры логики необходима система $F I V E$ пятизначной логики (из-за наличия лжи-нонсенса $\mathbf{F}^{\prime}=-1^{\prime}=\frac{1}{-1}$ и лжи-ошибки $\left.F=-1=\frac{-1}{1}\right)$. В ней при $b \geq a$ имеем $a \vee b=b$ и $a^{\prime} \vee b^{\prime}=b^{\prime}$. Самодуальность инверсии: $(a \vee b)^{\prime}=a^{\prime} \vee b^{\prime}$ облегчает покомпонентное выполнение операщий и упрощает запись.

В основе практической логики для компьютера лежат две пары противоположностей: по знаку имеем +1 и -1 , а по величине имеем нуль 0 и бесконечность $\frac{1}{0}$. Геометрической моделью может служить ситуация деления отрезка $[0 ; 1]$ в данном отношении.

\begin{tabular}{llllll}
$p=-\infty$ & 0 & $\frac{1}{2}$ & 1 & $+\infty$ \\
& $A$ & $\mid M$ & $B$ & \\
\hline$\frac{p}{q}=\frac{-1}{+1}$ & $\frac{0}{1}$ & $\frac{1}{1}$ & $\frac{1}{0}$ & $\frac{+1}{-1}$
\end{tabular}

Для отрезка $[A, B]$ отношение $\lambda=\frac{A M}{M B}$ удобнее задавать не одним числом, а парой чисел $\lambda=\frac{p}{q}[1]$. Имеют место два исключения:

1) точке $\mathrm{M}=\mathrm{B}$ не соответствует никакое $\lambda$,

2) число $\lambda=-1$ не соответствует никакой точке М.

Пара $\frac{p}{q}=\frac{1}{0}$ снимает первое исключение. Пополнив прямую несобственной (бесконечно удаленной) точкой, снимаем второе исключение. При $p \rightarrow+\infty$ имеем $\frac{p}{q}=\frac{+1}{-1}$, а при $p \rightarrow-\infty$ получаем $\frac{p}{q}=\frac{-1}{+1}$. Внутренность отрезка $[A, B]$ дает положительное значение $\lambda$, а внешность этого отрезка - отрицательное значение $\lambda$. Склеивание двух различных отношений $\frac{-1}{1}$ и $\frac{1}{-1}$, которое происходит при замене их одним числом -1 , порождает парадокс А. Арно, автора «Логики Пор-Рояля»: «меньшее относится к большому так же, как большее относится к меньшему», - 
который доказывал парадоксальность отрицательных чисел [3]. Однородные координаты позволяют сформулировать не только основания геометрии, но и основания логики.

\title{
2 Логический квадрат и матрица комплементарности
}

\author{
C'est peut-être I Ching qu'il faudrait étudier \\ pour saisir les relations entre hérédué et langage. \\ F.Jacob. Le modele linguistique en biologie. \\ (Возможно, именно через древнекитайскую \\ «Книгу перемен» удастся установить связь \\ между генетическим кодом и языком. \\ $\Phi$. Жакоб. Лингвистическая модель в биологии)
}

Под влиянием древнекитайской «Книги перемен» Лейбниц создал двоичную систему и поставил проблему создания универсального языка. Он писал: «Никто, однако, не попытался создать язык или характеристику,... знаки, или характеры которой представляли бы собой то же, что арифметические знаки представляют собой в отношении чисел, а алгебраические обозначения - в отношении абстрактно взятых величин» [14]. Нобелевский лауреат по молекулярной генетике Ф. Жакоб недаром возлагал такие большие надежды на древнекитайскую «Книгу перемен».

При создании универсального языка существенную помощь может оказать рассмотрение параллелизма между триплетами генетического кода и триграммами (с прерывистыми и сплошными чертами) из древнекитайской «Книги перемен». «Донышкам» - триграммам с двумя и одной сплошными нижними чертами - соответствуют минимумы: $\overline{\boldsymbol{二}}=\bigcup$ и $\boldsymbol{\Xi} \mathbf{E}=\bigvee$. Следуя 3. Фрейду можно охарактеризовать эти символы как вагиналь-

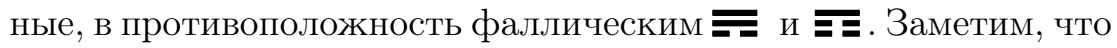
для слабых знаков масоны использовали усеченные треугольники. Аналогичный гендерный смысл несут и символы карточных мастей - Кубки (червы) и Мечи (пики), которые напоминают две пирамиды на входе Лувра: $\triangle$ и $\nabla$. Термин «угол вершиной вниз» звучит парадоксально, ибо «высота» фактически оказывается глубиной относительно «основания» (под-лежащее = субб-ект). Знаки экстремумов фактически являются символами слабого и сильного пола. Экстремумы подразделяются на глад- 
кие (первая производная $\left.y^{\prime}=0\right)$ и острые $\left(y^{\prime}\right.$ не существует). Имеем минимумы: $\bigcup-\partial н о$ и $\bigvee-$ бездонное дно.

Г. Фреге в «Логике» писал: «Законы природы не нуждаются в нашем признании, чтобы быть истинными». За образец букв универсального языка возьмем буквы генетического кода. Будем использовать букву $\mathbf{A}$ (аденин) как знак максимума, а букву $\mathbf{u}$ (урацил) как слабого минимума. Для другой комплементарной пары возьмем аналогичные перевернутые знаки: букву $\mathbf{V}$ как знак минимума (цитозин), а букву $\mathbf{n}$ как стилизованный знак слабого максимума (гуанин) [4]. Максимум $\mathbf{\Xi}=$ А и минимум $\mathbf{\Xi}=\mathrm{V}$ хорошо прорисовываются триграммами.

Теперь получаем Генетическую Матрицу Комплементарности (слева), которая заменила Логический Квадрат Противоположностей (справа).

\begin{tabular}{|c|c|c|c|}
\hline \multirow{2}{*}{$B$} & $\mathrm{n}$ & $\mathbf{A}$ & \multirow{2}{*}{3} \\
\cline { 2 - 3 } & $\mathbf{V}$ & $\mathrm{u}$ & \\
\hline CB & \multicolumn{2}{|c|}{$C$} & $\mathrm{C} 3$ \\
\hline
\end{tabular}

\begin{tabular}{|c|c|c|c|}
\hline TB & \multicolumn{2}{|c|}{$T$} & TC \\
\hline \multirow{2}{*}{$B$} & $\mathrm{n}$ & $\mathbf{A}$ & \multirow{2}{*}{$C$} \\
\cline { 2 - 3 } & $\mathrm{u}$ & $\mathbf{V}$ & \\
\hline $\mathrm{XB}$ & \multicolumn{2}{|c|}{$X$} & $\mathrm{XC}$ \\
\hline
\end{tabular}

Согласно восточной классификации элементы образуют две пары. Имеем по вертикали: теплое $(\mathrm{T})$ - холодное $(\mathrm{X})$, а по горизонтали: сухое $(\mathrm{C})$ - влажное $(\mathrm{B})$. Соединяясь попарно, эти свойства порождают четыре стихии: воздух (ТВ), огонь (ТС), вода (XВ), земля (XC).

Логический Квадрат (справа) является искусственной логической конструкцией, порождающей возникновение точки разрыва (второго рода). Достаточно сделать транспозицию элементов в нижней строке, своеобразную «рокировку», и полученная Матрица Комплементарности (слева) свободна от этого недостатка. В Квадрате Противоположностей по вертикальной оси имеем истину (t), а по горизонтальной - железную необходимость $(\mathrm{L})$, которой по древнекитайской классификации элементов соответствует 5-й элемент - металл. В этой классификации противопоставляются дерево и металл, которым соответствуют в Логическом Квадрате возможность и необходимость. В его правом столбце имеем необходимую истину Lt и необходимую ложь Lf. 


\begin{tabular}{|c|c|c|c|}
\hline Mt & \multicolumn{2}{|c|}{$t \equiv$} & Lt \\
\hline None & $\bar{\equiv}$ & $\equiv$ & Both \\
\hline$\equiv \equiv$ & $\underline{\bar{E}}$ & $\equiv \equiv$ & $\equiv$ \\
\hline Mf & \multicolumn{2}{|c|}{ f } & Lf \\
\hline
\end{tabular}

Поиск в языке априорных структур призван объяснить возможность математического знания. Одно слово «indefinite» во французском и английском языках имеет два значения: «неопределенно» и «безгранично». Им соответствуют None - логический нуль 0 и обратное значение Both - логическая бесконечность $\frac{1}{0}$, нонсенс. Это - противоположности по величине, а другая пара противоположностей: по знаку +1 и -1 .

Две указанные пары противоположностей лежат в основе Квадрата Противоположностей (Square of Opposition), обычно называемого Логическим Квадратом. Напротив, Матрица Комплементарности плавно вписывается в природные круговороты: годовой Солнечный цикл времен года (весна - лето - осень - зима) и месячный цикл фаз Луны: от первой четверти :) до последней четверти. Заметим, что символы лунных фаз могут быть прочитаны как смайлики. Итак, имеем модель, в которой сезоны перемежаются с деми-сезонами. Природа действительно движется по кругу, что соответствует матрице комплементарности. Круговая планировка Москвы (напоминающая кольца на спиле дерева) живая в отличие от прямолинейной планировки Санкт-Петербурга.

Логика кладется в основу искусственного интеллекта (ИИ), присущего компьютеру. Недаром девиз Лейбница был: Calculemus!, что означало Вычислим, чтобы не спорить. Ведь, логика это просто. Гораздо сложнее постигнуть природу естественного интеллекта (ЕИ). Живые системы требуют генетического подхода. Генетический код позволяет заглянуть в Кухню Природы, познавая принципы становления нового. Это - генеральная линия в преодолении пропасти между ИИ и ЕИ. Мы опираемся на идею структурирования по типу Матрищъ Комплементарности (Matrix of Complementary), имеющей естественное расположение элементов комплементарных пар.

Целостный блок $\Psi$ характеризует зависимость от фамилийдоминант «либералов» А и «консерваторов» V; а расщепленный 
блок $(\downarrow \uparrow)$ - зависимость от имен-доминант столбцов комплементарных пар $\downarrow$ и $\uparrow:$

$$
\downarrow=\begin{array}{|c|}
\hline \mathrm{n} \\
\hline \mathrm{V}
\end{array}
$$

Некронекеров (левый) тензорный квадрат матрицы $\Psi$ дает

\begin{tabular}{|c|c|c|c|c|c|c|c|c|c|c|}
\hline \multirow{2}{*}{ n } & \multirow[b]{2}{*}{ - } & & $\mathrm{nn}$ & $\underline{\mathrm{An}}$ & $\underline{\mathrm{nA}}$ & $\mathbf{A A}$ & gly & $\underline{\text { STOP }}, \underline{\text { arg }}$ ser & glu/asp & lys \\
\hline & & & $\mathrm{Vn}$ & un & VA & $\underline{\mathrm{uA}}$ & $\arg$ & STOP, trp/cys & gln / his & STOP/tyr \\
\hline & & & $\mathrm{nV}$ & $\mathrm{AV}$ & nu & $\underline{\mathrm{u}}$ & ala & thr & val & ile, $r$ \\
\hline & & & VV & $\mathrm{uV}$ & $\mathrm{Vu}$ & uu & pro & se & & leu/phe \\
\hline
\end{tabular}

Комплементарные пары образуют сочетания твердого характера с мягким. Рассматривая пары вида $\left(x_{1}, x_{2}\right)=($ First Name, Second Name), будем исходить из приоритета фамилии, второго имени (second name). Имеем две доминантные фамилии: гласная *A (вершина либерализма «полигамна», открыта) и согласная *V (воронка консерватизма «моногамна», закрыта). Не-доминантные фамилии $\mathrm{n}, \mathrm{u}:$ с гласными именами $\mathrm{A}^{*}, \mathrm{u}^{*}$ - аура золотой пары - примыкают к блоку гласных, а с согласными именами $\mathrm{V}^{*}, \mathrm{n}^{*}-$ волей-неволей к блоку согласных [5]. Так реализуется своеобразная петля гистерезиса (которая в Генетической таблице хорошо видна по блокам, напечатанным жирным и тонким шрифтом).

Перехлесты в петле гистерезиса описывают особенность порогового подхода. Это - аналог закона инерции в психофизике, где его сравнивают с работой реле. При решении практических задач в радиолокации для различения ситуаций «перехлеста» используется очень наглядная терминология: $\mathbf{N o}$ signal = пропуск сигнала (ОИ = отвергнутая истина) и Yes $/$ noise = ложная тревога (ПЛ = принятая ложь). В математике их называют ошибками первого и второго рода. Психологам хорошо известно, что в развлечениях быстрее вскрываются плюсы, а в проблемах - минусы.

Первым почти универсальным языком явилась математика, которая проявила тенденцию к захвату различных областей знания. «Усвоив с детства позиционный способ нумерации, мы 
склонны недооценивать это замечательное культурное достижение человечества. История, однако, учит нас, что такие высококультурные народы древности, как египтяне и даже греки с их изумительно тонкой и глубокой математической культурой, не создали позиционной нумерации». В средние века специальным декретом венецианской республики запрещались арабские цифры и вменялись к употреблению римские цифры. Умевшим делить в столбик числа, записанные римскими цифрами, даже присваивалась ученая степень - доктор деления.

Символическая информация непозиционна. Трудно составить звуковые слова из знаков арифметических действий, используя позиционный принцип. Нео-пифагорейская парадигма новой метафизики стала особенно популярна после открытия генкода, кода Живого. Геном выступает как образец текста, записанного четырьмя буквами универсального кода. Генетический код позволил нам заглянуть в кухню Природы и познать принципы становления нового. Не надо новых букв при позиционной записи операторных слов на высших уровнях, где достаточно всего четырех букв. При этом сначала идет крупноблочное строительство логической матрицы, а потом обустройство отдельных ячеек, которые заполняются по принципу подобия.

Нечисловой позиционный принцип в гуманитарной области дает не меньшие преимущества, чем позиционная числовая арифметика. В универсальном языке операторные слова составлены из однобуквенных операторов («букв»). Это реализует мечту Лейбница - сделать математику действительно универсальным языком. В инициалах (First Name, Second Name) фамильное сходство («типаж») играет роль ключевого аспекта, который стоит всех остальных вместе взятых. Кстати заметим, что при позиционной записи чисел арабскими цифрами старшинство разрядов возрастает справа налево, соответствуя записи арабских, а не европейских слов. И чтобы разобраться в логике генетического кода, надо все переставить с головы на ноги, ибо как говорят англичане: Last but not least (Последний по очередности, но не по значимости).

Д. Хофштадтером убедительно показана необходимость осмысления макроуровня генетического кода и подчеркивается необходимость перехода от молекулярного уровня к антропо- 
морфному - от молекул к характерам. Центральные строительные блоки личности - характер и темперамент - имеют решающее значение во взаимопонимании. Это очень важно, ибо главное не технология и не финансы, а битва за умы, позиционирование сознания [22]. Высший уровень позволяет выявлять смыслы макроскопических сущностей-единств, напечатанных тонким шрифтом как КОНСеРвАтивныЕ, а жирным шрифтом как мутационные, «полигамные» ячейки (таблица слева), порождающие кодоны более богатые аминокислотами (таблица справа) $[7,8,20]$. Феноменология дает понимание кода психотипа.

Противоположность между консерватизмом $V$ и авантюризмом $\underline{\boldsymbol{A}}$ наглядно проявляется в хромосоме 19 , где замена двух цистинов на два аргинина (в позициях 472 и 334 в тексте гена $\mathrm{ApoE} \varepsilon 4$ длиной в 897 «букв») приводит к увеличению риска заболевания болезнью Альцгеймера в 2 раза, а в сочетании с травмой головы в 10 раз [2].

Изоморфизм матриц генетического кода и психических типов показывает предрасположенность характеров, во многом определяющихся их генетическим кодом. Однако матрица, лежащая в основе классификации в книге О. Крегера и Дж. Тъюсона [12], меня не удовлетворила. Не было изоморфизма с моей таблицей генетического кода. Систематизация такого известного специалиста, как В.В. Гуленко, с 4-я блоками (профклубы), использовавшаяся Е.С. Филатовой и Н.Ф. Тельновым, оказалась наиболее удачной $[17,6]$.

Вопрос о структурном изоморфизме психических, физиологических и природных феноменов рассматривался еще в античности. Начиная с Гиппократа выделяли четыре темперамента, аналогичные агрегатным состояниям вещества. Пути решения проблемы «Двух культур» Ч. Сноу намечает в романе «Поиски»: «Нам всем хочется чего-то такого, чего наука не может дать нам... те образы, в которых греки воплощали природу: земля, воздух, огонь и вода».

В основу классификации психологических типов положено дихотомическое деление. Таблица основана на двух парах противоположных факторов: S-N (Sensation-Intuition) и T-F (Thinking-Feeling). 


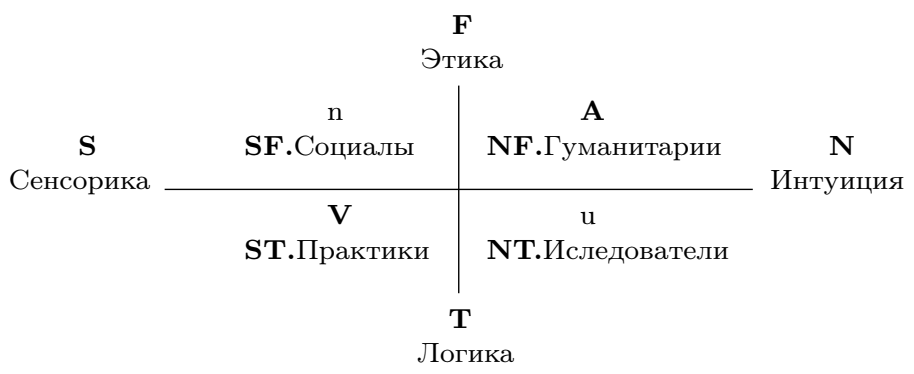

В таблице легко распознается Матрица Комплементарности с четырьмя первоэлементами-мастями: черви, бубны, трефы, пики $-\varnothing \diamond \boldsymbol{p}$.

\begin{tabular}{|c|c|c|c|c|c|c|c|}
\hline$n$ & A & Медиа & Артисты & $\diamond$ nар пиара & ○ Огонь страсти|, & :) весна & ○ Лето \\
\hline $\mathrm{V}$ & $u$ & Власть & Ученые & Љ Лёд власти & \& вода науки & - Зима & :( осень \\
\hline
\end{tabular}

Освежающий вдох свежего дыхания, обжигающий огонь страсти, живительная вода мудрости и, наконец, леденящий холод могильных памятников - таковы фазы жизненного цикла.

Матрица состоит из четырех блоков психотипов, каждый из которых является ею в миниатюре, действуя как фрактальный умножитель. Добавляя третью пару противоположных факторов на Е-I (Extravertion-Introvertion) получаем психологические типы К. Юнга. Он считал основным деление на экстраверсию и интроверсию (E-I) и рассматривал его в сочетании с вышеозначенными S-N и F-T. Юнг вводит и четвертую дихотомию «рационализм-иррационализм», а Майерс и Майерс-Бригс заменяют ее на производную J-P (Judging-Perceiving) - комбинацию «рационализма-иррационализма» с экстраверсией-интроверсией (под предлогом ее якобы большей внешней проявленности). Научный руководитель журнала «Соционика и психология» Р.А. Степанов, анализируя четвертую дихотомию, показал необходимость ее замены на пару противоположностей O-A (Mobile-Stabile) Динамик-Cтатик [16], обосновывая первичность этой дихотомии и вторичность дихотомии «рациональность-иррациональность». Он выделяет 4 первичных дихотомии: E-I, S-N, F-T, O-А. Динамик делает встречные шаги (в прямом и переносном смысле), а для статика характерна согнутость фигуры и угловатость движений [13]. Доминанты A,V 
образуют блок аристократов, которые четко делят всех на «своих» и «чужих». Для противостоящего им блока демократов $\mathrm{n}$, u отсутствуют авторитеты, особенно у иррационалов.

Каждый блок может быть подразделен на психовиды, что порождает таблицу с шахматным порядком для ИНТРОВЕРTОВ $(\mathbf{6})$ и экстравертов $(\boldsymbol{м})$. Итак, получаем Основную Матрицу:

\begin{tabular}{|c|c|c|c|c|}
\hline & Статик & Динамик & Статик & Динамик \\
\hline & Наполеон & ДЮМА & Гексли & ЕСЕНИН \\
\hline & ДРАЙЗЕР & Гюгго & ДОСТОЕВСКИЙ & Гамлет \\
\hline & Жуков & ГАБЕН & Дон Кихот & БАЛЬЗАК \\
\hline & МАКСИМ & Штирлич, & РОБЕСПЬЕР & Джек \\
\hline
\end{tabular}

Для рационалов характерно совпадение: ИНТРОВЕРТ = статик, а экстраверт = динамик. Рациональные экстраверты динамики (Гюго, Гамлет, Джек, Штирлии) страдают излишним консерватизмом. Рационалы тяготеют к стандартизации, интроверты замкнуты. Рациональные интроверты статики (ДРАЙЗЕР, МАКСИМ, ДОСТОЕВСКИЙ, РОБЕСПЬЕР) имеют склонность к формализму. Если рационал все планирует, то иррационал действует спонтанно. Согнутость и угловатость движений - характерные внешние признаки статика Дон Кихота - смягчаются для иррационала встречной открытостью экстраверта. Это - творческий тип искателя. Его полная противоположность из блока ученых - БАЛЬЗАК. У него как иррационала плавность движений динамика ожесточается замкнутостью интроверта. Он менее инициативен и является скорее критиком.

Приведенные персонажи - это своего рода фотороботьи, которые носят характер псевдонимов, принятых в сленге социоников. Они были предложены Аушрой Аугустинавичюте, которая открыла отношения социальной ревизии и заказа как базовых интертипных отношений и показала асимметрию этих отношений.

А. Аугустинавичюте выявила в популяции, состоящей из 16 психотипов, группу из 14 так называемых «интертипных отношений», определенным образом структурирующих взаимодействие членов популяции. Причем, 2 из 14 отношений в этой груп- 
пе являются асимметричными, и образуют в популяции циклические структуры одностороннего движения информации, названные «кольцами социального заказа». и «кольцами социальной ревизии».

Социальная ревизия является отношением контроля, где в качестве опорного признака Г.Р. Рейнина рассматривается пара позитивность $(+)$-негативность $(-)$. Позитивисту в данный момент времени бросаются в глаза положительные, а негативисту - отрицательные аспекты ситуации. Ревизные отношения всегда очень тяжелые, причем нажим происходит от ревизора к подревизному. Обычно ревизор недооценивает способности своего подконтрольного, который со своей стороны недостаточно ценит проявляемую заботу.

Социальный заказ как отношение передачи информации (от передатчика к приемнику) является более благоприятным, чем ревизия. В качестве опорного признака для него рассматривается пара квестимность(?)-деклатимность(!). Коллектив заказного типа склонен к традиционному долгу, дискуссии в нем мало эффективны. Например, консервативный рационал Штирлиц является заказчиком для творческого иррационала Дон Кихота. Оба они экстраверты-квестимы, что более благоприятно для совместной работы. Для квестима спор не самоцель, а является способом получения информации, он не склонен к декларативности. Дополнительные спирали будут кольцами деклатимного(!) заказа. Наиболее комфортными являются отношения дуалов - недаром говорят: крайности сходятся. Таковы например, два иррационала: экстраверт статик Дон Кихот и интроверт динамик ДЮМА. Это, например, я и моя внучка.

Открытие Аугустинавичюте феномена «интертипных отношений» имеет регистрацию от 1 октября 1980 г. по дате депонирования ее рукописи «Теория интертипных отношений» в отделе рукописей Библиотеки АН Литовской ССР. Сущность открытия: «Установлено неизвестное ранее явление самоорганизации динамических структур межличностного взаимодействия в человеческом обществе, заключающееся в том, что в группе индивидуумов устанавливается определенная динамическая структура взаимодействия (пространственное расположение партнеров, интенсивность, темп и другие параметры речевого обмена, со- 
ответствующая продуктивность совместной деятельности, субъективные переживания и др.), обусловленная дифференциацией человеческого общества на кооперирующие психологические типы личности».

Учет базовых интертипных отношений позволил построить с помощью периодического сдвига в Основной Матрице Периодическую таблицу, которая открывает «царский путь» в изучение отношений социальной ревизии и социального заказа. В предлагаемой ПСИ-таблице прослеживается четкая классификация в терминах Рационалов-Иррационалов и Статиков-Динамиков. Это - шахматная доска с клетками экстравертов-ИНТРОВЕРТОВ (черные клетки, большие буквы).

В таблице КлЕТки заказа прочитываются по всем линиям вверх:

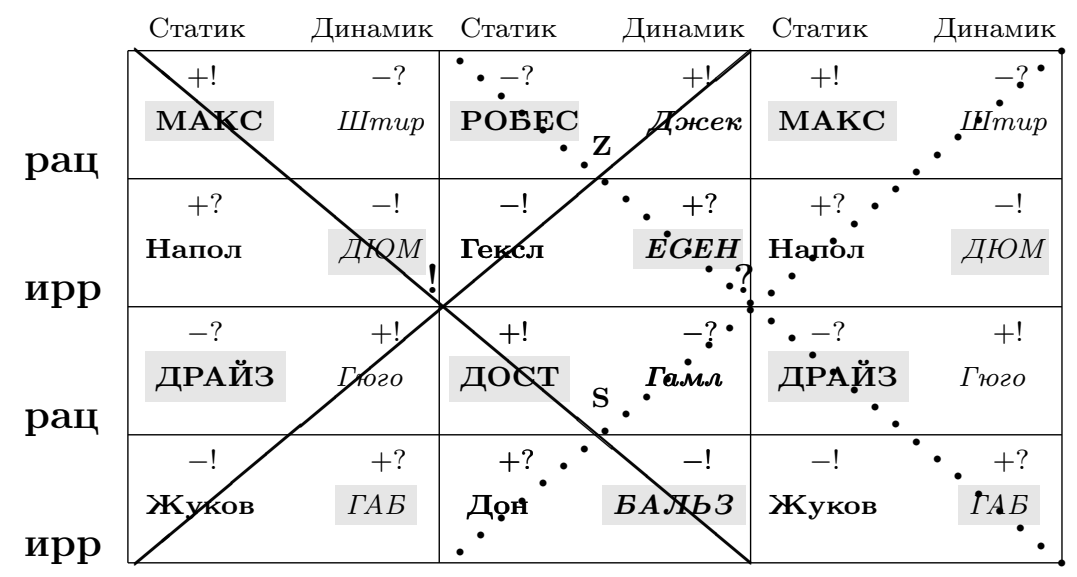

Блоки по любым линиям (по сплошным или по пунктирным) вниз дают пары параллельных линий ревизии:

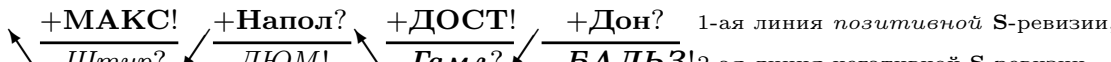
-Штир? -ДЮМ! -Гамл? -БАЛЬЗ!2-ая линия негативной $\mathrm{S}$-ревизии,

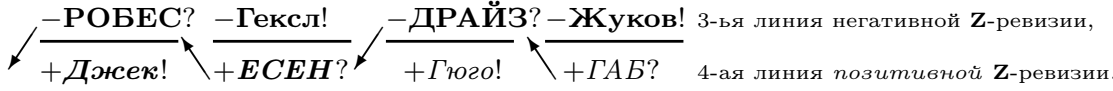

Кольца социальной ревизии пронизывают все четыре блока. Два кольца идут в одном направлении, два других - навстречу. 
S-ревизия образует кольцо с вращением по часовой стрелке, что соответствует известному знаку свастики [19]. Примером может служить кольцо негативистов: БАЛЬЗАК давит на Штирлица, Штирлиц на ДЮМА, ДЮМА на Гамлета, Гамлет на БАЛЬЗАKA. Z-ревизия характеризует кольцо с вращением против часовой стрелки. Чередование ИНТРОВЕРТ (Б, черная клетка) экстраверт (м, белая клетка) характерно для циклов ревизии. Приведем паззлы $\mathbf{S}$-ревизии (рис. 1a) и $\mathbf{Z}$-ревизии (рис. 1б).

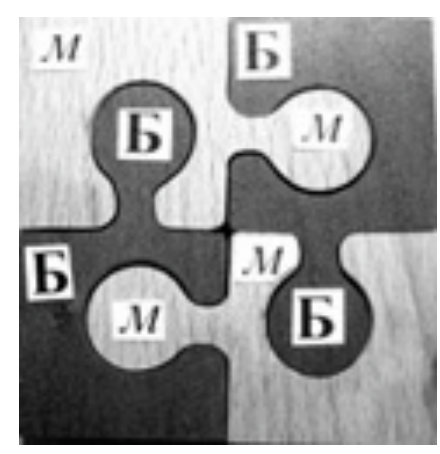

Рис. 1a

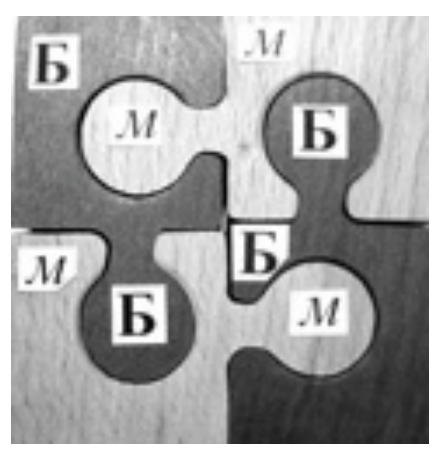

Рис. $1 б$

Коллектив с ревизуемостью дисциплинирован, его участники избегают генерировать идеи. Данный тип хорош для армейских коллективов. Например, рациональный экстраверт Штирлиц давит на иррационального интроверта ДЮМА (случай негативной $\mathbf{S}$-ревизии). Кольца социального квестимного (?) заказа образуют спирали, которые показаны стрелками. Например, Штирлиц передает заказ Дон Кихоту, Дон Кихот - Гамлету, Гамлет - Наполеону, Наполеон - Штирлицу.

Наглядно просматривается асимметрия социальной ревизии и заказа как базовых интертипных отношений. Мой опыт невольного участия в асимметричных отношениях позволяет заключить, что знание психотипов дает возможность понять тех, кто является подзаказным (я, например, по отношению к своему зятю), а также тех, кто находится в положении подревизного (внучка ДЮМА по отношению к своему отцу Штирлицу).

Люди подчас понятия не имеют о том генетическом «наследстве», которое они получили. Осознание того, что типажи ха- 
рактера являются врожденными, позволяет разуму найти решение проблемы. Моя многолетняя педагогическая практика показывает, как важно учитывать психотип каждого учащегося. Эти знания следовало бы преподавать уже в школе. В жизни они важнее биологии. Без учета человеческого фактора трудно представить себе подбор профессионального коллектива. Многие межличностные конфликты в служебной и семейной жизни находят свое разрешение. Приведу девиз Франка Милтнера и Вернера Сифеза: «Понимание самого себя и умение общаться с окружсающими - залог жизненного успеха», который был взят в качестве эпиграфа к последней книге профессора Н.Ф. Тельнова [6].

Матрица генкода и матрица психотипов обе построены на основе Матрицы Комплементарности. Ей противостоит Логический Квадрат, который является искусственной логической конструкцией. Г. Харди в «Курсе чистой математики» подчеркивает недоказательный характер геометрических интерпретаций и старается избегать чертежей. Напротив, автор известного учебника Г.М. Фихтенгольц утверждает: «Курс математического анализа не должен представляться учащемуся лишь длинной цепью "определений" и "теорем", но должен служить руководством к действию» [18]. Компьютерам пока недоступно творческое мышление, привлекающее внимание своей поразительной эффективностью благодаря парадоксальным метафорам. Мы приложим все усилия для решения этой задачи, превратим одномерного человекоподобного робота (single-minded, one-dimentional man), который, перебирая кирпичи, не дает никакого указания о способе кладки - в личность, обладающую метафорическим языком. Логические диаграммы Л. Кэрролла явились существенным прорывом и его популярная книга «Логическая игра» открывается посвящением «Моему другу маленькой девочке», напоминая детям и взрослым о жизнерадостной и находчивой Алисе. Ю.И. Манин считает, что Логический Квадрат заковывает милую девочку в тяжелые латы Белого Рыцаря и призывает «увидеть в математике воспитателя образного мышления» [15]. Абсолютизация памятника замораживает движение, так как пьедестал мешает двигаться. «Не надо заводить архива, над рукописями трястись» (Б. Пастернак). 


\section{3 Арифметизация модальной логики}

Nature moves in circles; art in straight lines. The natural is rounded; artifical is made up of angles. O. Henry. Squaring the circle.

(Природа движется по кругу. Искусство по прямой линии. Все натуральное округлено. Все искусственное угловато. О. Генри. Квадратура круга)

Генетическая Матрица Комплементарности (слева) хорошо описывает круговую упорядоченность элементов, поскольку она не имеет точки бесконечного разрыва $\pm \infty= \pm \frac{1}{0}= \pm 0^{\prime}$, которая характерна для Логического Квадрата (справа). Окрестность бесконечности является антиподом окрестности нуля \pm 0 .
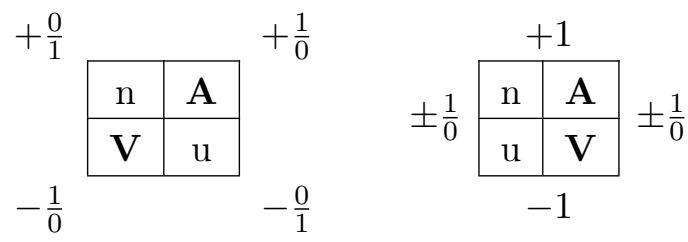

Логический Квадрат является искусственной логической конструкцией, демонстрирующей зияющие высоты классической логики. Достаточно сделать «рокировку», и в полученной Матрице Комплементарности удается устранить соседство необходимой истины Lt $=\frac{+1}{0}=+0^{\prime}$ и необходимой лжи $\mathrm{Lf}=\frac{-1}{0}=-0^{\prime}$. Можно наглядно усмотреть сходство и отличие от четырехзначной логики Белнапа. Будем отталкиваться от матричного метода, примененного для четырехзначной логики Лукасевичем [11]. В его четырехзначной модальной логике, первоначально опиравшейся на числовую бинарность, в отличие от Буля принимается: ИСТИНА $=(1,1)=1$, ЛОЖЬ $=(0,0)=0$. Кроме того, имеются дополнительные значения истинности $(1,0)=2$ и ложности $(0,1)=3$, которые не получают более конкретной интерпретации. Принятая сплошная нумерация носит формальный характер и не позволяет усмотреть естественную упорядоченность. Поэтому в дальнейшем различными авторами им, как промежуточным значениям, приписывались дробные значения $\frac{1}{3}$ и $\frac{2}{3}$, что означало полный отказ от концепции булевой многозначности, 
исповедующей принцип цифровой бинарности (только цифры 0 и 1).

Автор по-прежнему предлагает для обозначения ложности использовать отрицательные числа. Геометрической моделью снова будет служить ситуация деления отрезка $[0 ; 1]$ в данном отношении $\lambda=\frac{p}{q}$.

\begin{tabular}{|c|c|c|c|}
\hline \multirow[t]{2}{*}{$p=-\infty$} & 0 & $\frac{1}{2}$ & 1 \\
\hline & $A$ & $M$ & $B$ \\
\hline$\frac{p}{q}=$ & $\begin{array}{l}\frac{-0}{1}, \frac{+0}{1} \\
\text { Mf, Mt }\end{array}$ & & $\begin{array}{l}\overline{0}, \frac{1}{-0} \\
t, \mathrm{Lf}\end{array}$ \\
\hline
\end{tabular}

В модальной логике не будут использоваться оба исключения, ведь точке $\mathrm{M}=\mathrm{B}$ не соответствует никакое $\lambda$, а числу $\lambda=-1$ не соответствует никакая точка М. Внутренность отрезка [A, B] дает положительные значения $\lambda$, а внешность этого отрезка отрицательные значения $\lambda$. При стремлении слева к точке $\mathrm{B}$, $p \rightarrow 1-\varepsilon($ где $\varepsilon \rightarrow 0)$ имеем необходимую истину Lt $=\frac{1}{+0}=+0^{\prime}$, а при стремлении справа, $p \rightarrow 1+\varepsilon$ имеем необходимую ложь $\mathrm{Lf}=\frac{1}{-0}=-0^{\prime}$. При стремлении слева к точке $\mathrm{A}, p \rightarrow-0$ имеем возможную ложь $\mathrm{Mf}=\frac{-0}{1}$, а при стремлении справа, $p \rightarrow+0$ имеем возможную истину $\mathrm{Mt}=\frac{+0}{1}$.

Унарные связки для логической инверсии «'» и отрицания «-» определяются следующей таблицей:

\begin{tabular}{|c|c|c|}
\multicolumn{1}{c}{} & \multicolumn{1}{c}{$A^{\prime}$} & $-A$ \\
\hline$+0=\frac{+0}{1}$ & $+0^{\prime}=\frac{1}{+0}$ & $-0=\frac{-0}{1}$ \\
\hline$-0=\frac{-0}{1}$ & $-0^{\prime}=\frac{1}{-0}$ & $+0=\frac{+0}{1}$ \\
\hline$+0^{\prime}=\frac{1}{+0}$ & $+0=\frac{+0}{1}$ & $-0^{\prime}=\frac{1}{-0}$ \\
\hline $0^{\prime}=\frac{1}{-0}$ & $-0=\frac{-0}{1}$ & $+0^{\prime}=\frac{1}{+0}$ \\
\hline
\end{tabular}

Приведем для дизъюнкции нашу итоговую таблицу (слева) и таблицу для модальной логики Ю.В. Ивлева [10], которая для удобства сравнения дана в наших обозначениях (справа): 


\begin{tabular}{cccccccccc} 
& Mf & Mt & Lt & Lf & & Mf & Mt & Lt & Lf \\
$\vee$ & -0 & +0 & $+0^{\prime}$ & $-0^{\prime}$ & $\vee$ & -0 & +0 & $+0^{\prime}$ & $-0^{\prime}$ \\
Mf, -0 & -0 & +0 & 1 & 1 & -0 & -0 & +0 & $+0^{\prime}$ & -0 \\
Mt, +0 & +0 & +0 & 1 & 1 & +0 & +0 & +0 & $+0^{\prime}$ & +0 \\
Lt, $+0^{\prime}$ & 1 & 1 & $+0^{\prime}$ & $+0^{\prime}$ & $+0^{\prime}$ & $+0^{\prime}$ & $+0^{\prime}$ & $+0^{\prime}$ & $+0^{\prime}$ \\
Lf, $-0^{\prime}$ & 1 & 1 & $+0^{\prime}$ & $-0^{\prime}$ & $-0^{\prime}$ & -0 & $+0^{\prime}$ & $+0^{\prime}$ & $-0^{\prime}$ \\
\hline
\end{tabular}

Например, равенство $+0 \vee+0^{\prime}=1$ вполне соответствует известному соотношению $N \vee B=T$ логики Белнапа. Очевидно $a \vee b^{\prime}=1$, ибо $\frac{a}{1} \vee \frac{1}{b}=\frac{1}{1}$. Ложное значение $-0 \vee-0^{\prime}=-0$ в правой таблице не вписывается в это правило. В этом случае правая таблица оказывается «неправой», ибо нарушается принцип покомпонентного выполнения операций. Ведь только его выполнение позволило завязать все в единый логический узел, реализовав универсальный подход к арифметизации практической логики Белнапа и модальной логики.

Автор выражает скромную надежду, что ГЕНЕТИЧЕСКИЙ ПОДХОД В ЛОГИКЕ позволит воочию увидеть замысел Природы и окажется в первую очередь полезным для тех приложений, которые привели к мысли о необходимости перехода от Логического Квадрата к Генетическому Кругу.

\section{Литература}

[1] Александров П.С. Лекции по аналитической геометрии. М, 1949. С. 28.

[2] Александров А.А. Психогенетика. СПб, 2008. С. 85.

[3] Бахтияров К.И. Алгебра логики для компьютера // Смирновские чтения. 4-ая Международная конференция. М., 2003. С. 25-27.

[4] Бахтияров К.И. Логическая многомерность (векторные и матричные модели) // Вестник МГУ. Сер.7. 2005. №5. С. 92.

[5] Бахтияров К.И. Принципы универсального языка (позиционная доминантность и фрактальность) // Противоположности и парадоксы. М., 2008. С. 216233.

[6] Бахтияров К.И. Роль гуманитарных трудов профессора Н.Ф. Тельнова в естествознании // Международный научный журнал. Министерство сельского хозяйства РФ. М., 2008. №4. С. 80.

[7] Бахтияров К.И. Квадрат Противоположностей и Матрица Комплементарности // Полигнозис, 2009. №4. С. 53-59.

[8] Бахтияров К.И. Матрица комплементарности для метагенетики // Смирновские чтения по логике. Материалы 6-ой конференции. Москва. 2009. С.154-156.

[9] Белнап H. Как нужно рассуждать компьютеру // Белнап Н., Стил Т. Логика вопросов и ответов. М., 1981. 
[10] Ивлев Ю.В. Модальная логика. М., 1991. С.76.

[11] Карпенко А.C. Развитие многозначной логики. М., 2010.

[12] Крегер О., Тъюсон Дж. Типы людей: 16 типов личности. М., 2006.

[13] Кривошеев E.M. Соционика глазами психолога. М., 2005. С.95.

[14] Лейбнии Г.В. Письма и эссе о китайской философии и двоичной системе исчисления. М., 2005. С. 7.

[15] Манин Ю.И. Математика как метафора. М., 2008. С.138.

[16] Степанов P.А. История четвертой дихотомии // Соционика и психология. М., 2001. C.20-35.

[17] Филатова E.C. Искусство понимать себя и окружающих. СПб, 1998.

[18] Фихтенголъи, Г.М. Основы математического анализа. М., 1960. Т.1. С. 11.

[19] Якубовская Т.С. Соционика: как разбираться в себе и в других. М., 2005. С.139143.

[20] Bakhtiyarov K.I. Matrix of Complementarity for Metagenetic // Symmetry Festival 2009. Abstracts. Budapest 2009.

[21] Feys R. Boolean Methods of Development and Interpretation // Proceedings of the Royal Irish Academy. 1955. Vo.57. Sect. A. №6. P. 111.

[22] Hofstadter D. I am a Strange Loop. N.Y., 2007. P. 235, 299. 